\section{THE HEAVENS IN JANUARY.}

If you step out of doors about 9 o'clock on a cloudess evening in the middle of January, and face the south, you will see before you the greatest of all the constellations, Orion. It is more than half way from the horizon to the zenith, and just east of the meridian. Whoever wishes to become acquainted with the finest display that the heavens afford, will do well to begin by fixing clearly in mind the outlines of Orion. It serves as a point of reference for the other constellations.

The first thing likely to arrest the eye is a beautiful row of three second-magnitude stars, nearly three degrees long, making the "Belt" of the giant figure which the ancients imagined here among the stars. The row s'opes downward to the left. Above it, in a direction at right angles to the line of the Belt, and about nine degrees away, gleams a splendid first-magnitude star of a slightly reddish color, Betelgeuse, or Alpha Orionis, while on the lower side of the Belt, and at a similar distance, is another first-magnitude star, of piercing whiteness, Rigel, or Beta Orionis. Betelgeuse is in the giant's right shoulder, and Rigel shines on his uplifted foot, as Albrecht Dürer drew the figure. for Flamsteed's Celestial Atlas.

Another second-magnitude star seven or eight degrees west of Betelgeuse marks the left shoulder. It is named Bellatrix, or the Amazon Star. A few degrees above a line drawn from Bellatrix to Betelgeuse is a little group of stars indicating the head.

Below the Belt, hanging straight down, nearly in a line with the head, appears another short row of small stars, the middle one of which has a hazy look. This is the Sword, and a telescope enlarges the hazy star into the grand Orion Nebula. About five or six degrees to the left of and below the point of the Sword is a lone third-magnitude star, Saiph, in the right linee. Betelgeuse, Belatrix, Rigel and Saiph mark the corners of a large trapezium, in the middle of which shines the Belt, and having once recognized this conspicuous figure, the observer will ever after know Orion.

Now, continue with the eye the line of the Belt downward and eastward, and at a distance somewhat more than twenty degrees you will encounter Sirius, by far the brightest star in the heavens. When near the horizon it is ablaze with prismatic colors, but as it rises higher the colors disappear, except for stray flashes like the rays from a fine diamond, and it settles down to a cold white core of luminous splendor. Prof. Newcomb estimates the actual luminosity of Sirius as thirty times that of the sun, but its spectroscopic constitution is different, and it is probably at an earlier stage of development. The striking figure formed by smaller stars southeast of Sirius marks the body of Canis Major, Sirius flaming in the mouth of the imaginary dog.

Directly under Orion's feet is the inconspicuous constellation of Lepus, the Hare. West of Lepus, wandering broadly over the sky, appears the long double-curve of Eridanus, the River Po, the line of its current being fairly well indicated by streams of small stars. Far over in the southwest, beyond the borders of Eridanus, is Cetus, the Whale, not very conspicuous at this season.

Returning to Orion and looking above him and westward, -we see, almost overhead, Taurus, the Bull, whose charge the giant is figured as withstanding, with uplifted club in his right hand, over Betelgeuse, and "with shield of lion's skin spread over his left arm, and indicated by a sprinkling of faint stars west. of Bellatrix. The "horns" of Taurus project over Orion's head, and each is tipped with a fairly bright star in the Milky Way, which passes above Orion, from southeast toward northwest.

The head of Taurus is brilliantly marked by the Vshaped figure called the Hyades, whose brightest star, of the first magnitude, is the celebrated Aldebaran. This star is red, of a deeper hue than Betelgeuse. In actual luminosity it about equals Sirius, but being much farther away appears less brilliant to us. It may be remarked here that Rigel, according to Newcomb's estimate, is immensely greater than Sirius, and possibly exceeds the sun in light ten thousand times! But its distance is too great to be measured with our present means.

West of the Hyades appears the sparkling cluster of the Pleiades, in the Bull's shoulder. Here the figure of Taurus is abruptly cut off, and next westward comes Aries, marked by a pair of stars four or five degrees apart. Beyond Aries Pisces extends to the western horizon, with no conspicuous stars, but made notable just now by the presence of the planet Jupiter, and by the advance of Venus from the sunward side.

A way overhead, north of Orion and Taurus, another brilliant first-magnitude star, Capella, in the constellation Auriga, attracts our eyes. East of Auriga the stars Castor and Pollux, in Gemini, are seen shinin about five degrees apart. Castor is the more northern and fainter one. Below them is seen the brilliant lone star Procyon in Canis Minor.
Following the Milky Way northwestward from $\mathrm{Ca}$ pella we see first the bending row of Perseus, with Algol hanging below; then the W-stesped figure of Cassiopeia; and south of Cassiopeia the row of secondmagnitude stars in Andromeda, terminating in the northwest with the great Square of Pegasus. Th Great Dipper is seen rising, bowl upward, in the northeast, while south of it is the Sickle of Leo.

$$
\text { THE PLANETS. }
$$

Jupiter and Venus play the principal parts in the planetary display for January, and both are very brillant. Saturn is also our evening star, but, having bee in conjunction with Venus late in December, it is now drawing close to the sun and will disappear in hi rays early in February.

To see Jupiter and Venus it will be best to choos an earlier hour than that selected for the constellation -say between 7 and 8 o'clock. Between 6 and 7 would be even better.

Jupiter remains in Pisces, moving very slowly eastward, but Venus which, on the 1st of January, is i Capricornus, rapidly swings away from the sun, advancing by the 15th to the center of Aquarius, and entering Pisces before the close of the month. Sh seems to be hastening to overtake her great brother, and her brightness grows from night to night as she hurries eastward. On the 1st she hardly outshines Jupiter, but as more and more of her illuminated surface comes into view from the earth, and as, at the same time, she gradually draws nearer, her superiorit in brilliance to her really greater but more distant rival, will become strikingly evident. To watch these two planets through January will be an object lesson in celestial motion

Mercury is in the morning sky, at greatest elonga-

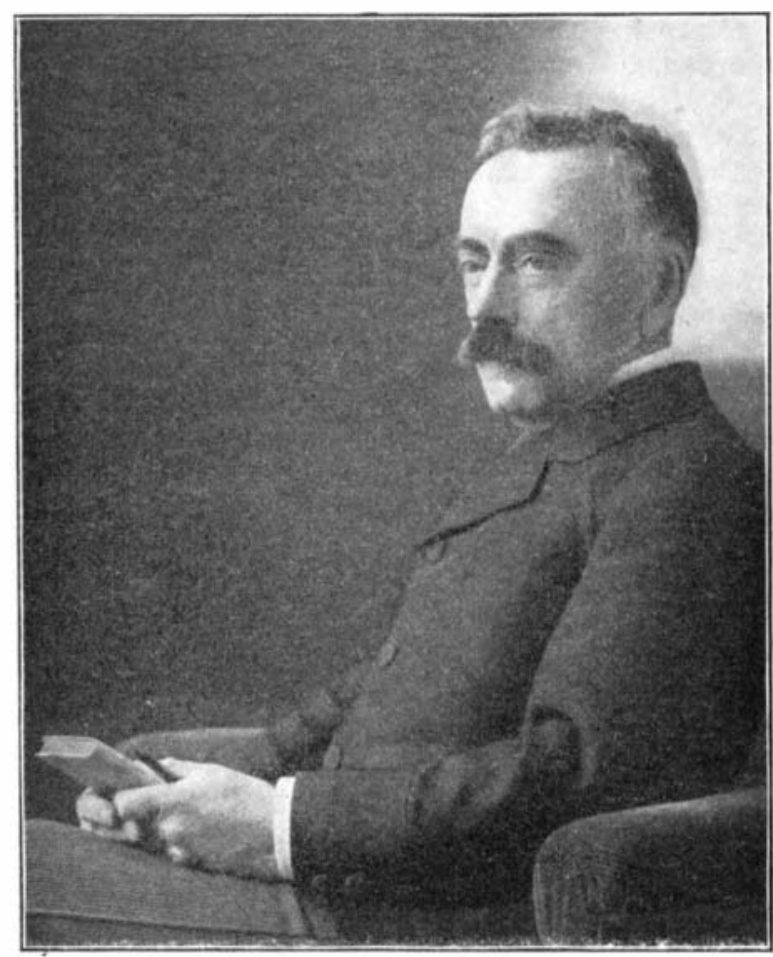

WILLIAM GILSON FARLOW.

Newly-elected President of the American Association for the Advancement of Science.

tion from the sun on the 22d. Mars is also a morning star, in the eastern part of Virgo, rising about $1 \mathrm{~A}$. M. in the middle of the month.

THE MOON.

New moon occurs on the 5.th about 1 P. M.; first quarter on the 13th, about 3 P. M.; full moon on th 21 st, about $2 \mathrm{~A}$. M.; and last quarter on the $27 \mathrm{th}$, about 7 P. M. The moon is farthest from the earth on the $12^{\text {th }}$ and nearest on the 23d. The lunar planetar conjunctions occur as follows in Washington mean time: Mercury, January 4, 5:52 P. M.; Saturn, January 8, 8:41 A. M.; Venus, January 9, 10:06 A. M. Jupiter, January 13, 10:33 A. M.; Neptune, January 19, 8:53 A. M.; Mars, January 27, 4:34 P. M.; Uranus, January $31,9: 22$ P. M.

The interesting discovery of a "rill," or "crack," eighty miles in length, lying in the axis of the great lunar Valley of the Alps, is announced from the Lick Observatory. This may have been the bed of a river.

\section{WILLIAM GILSON FARLOW.}

Botany has always been a favorite study in this country and there have always been masters to teach it. Throughout the English-speaking world, whether in our own country or abroad, the standard textbooks on botany are still those written by Asa Gray. Befor Gray, John Torrey, whose researches extended into other sciences as well, for he was equally distinguished as a chemist, was the great authority. These two men have filled the high office of President of the American Association for the Advancement of Science, and this year, at the Philadelphia meeting, William Gilson Farlow, one of Gray's pupils, and easily the foremost writer upon cryptogamic botany in the Uniled States, conferred upon a man of science in this country.

Prof. Farlow was born in Boston, Mass., on December 17, 1844, and after the usual preliminary studies entered Harvard College, where he was graduated in 1866 . He then spent four years in the medical department of that university, taking the degree of Doctor of Medicine in 1870. Having determined to devote himself to the study of botany, he then went to Europe, where he spent some time under the celebrated Henri A. de Bary at the university in Strasburg, and later studied under Eduard Bornet and Gustave Thuret in Paris

In 1874 he returned to the United States, and was appointed adjunct professor of botany at Harvard, and five years later was given the chair of cryptogamic botany, which place he stili fills, being now in length of service the senior professor in the Department of Botany of Harvard University.

It is difficult to speak of his many investigations, but they have been principally devoted to marine algæ, fungi, diseases of plants, and kindred subjects, the results of which are included under the following titles: The "Potato Rot," which appeared in 1875; "Diseases of Olive and Orange Trees" a year later; and in 1880 he published a paper on "The Gymnosporangia," which was followed by "The Marine Algæ of New England" in 1881; then on "Some Species of Gymnosporangium and Chrysomyxa of the United States" in 1885, and during the same year one on "Some Injurious Fungi of California," in which State he spent nearly a year, and some notes on "Arctic Algæ" in 1886.

Prof. Farlow has made studies in his specialties for the United States Fish Commission and the Massachusetts Board of Agriculture, the results of which have appeared in the reports of these bureaus. In the prosecution of these investigations Prof. Farlow has traveled extensively in this country and in Mexico, as well as in Europe.

In recent years, especially since the death of Prof. Gray, his professorial duties have largely increased, and his leisure has been devoted to the preparation of textbooks, especially one on Cryptogamic Botany which has been long expected. Its exact title is to be "Introauction to Cryptogamic Botany, both Structural and Systematic." Prof. Farlow must also be credited with the authorship of the accounts of the "Progress of Botany" which have appeared in the annual reports of the Smithsonian Institution during the years from 1879 to 1886 . He also prepared the review of the botanical work of that institution that appeared in the sumptuous volume published in celebration of the completion of the first fifty years of the Smithsonian Institution in 1897 .

Prof. Farlow is an active member of many scientific societies both in this country and abroad, including the American Academy of Arts and Sciences, and in 1897 he received an election to the National Academy of Sciences. He represented Harvard in the gathering of scientific men in Glasgow in 1901, and on that occa. sion received the honorary degree of. LL.D. from the university there. On the installation of President Van Hise of the University of Wisconsin in 1903, Prof. Farlow was again made the recipient of the honorary degree of LL.D.

He has been an active member of the American Association for the Advancement of Science since the meeting held in Indianapolis in 1871, and was advanced to the grade of fellow in 1875 . His interest and constant attendance at the meetings led to his election in 1897 to the vice-presidency over the Section of Botany, and at the meeting held in St. Louis during convocation week (1903-4) he was the unanimous choice of the members for the presidency of the association.

In addition to John Torrey and Asa Gray, who served as presidents of the American Association in the years 1855. and 1871 respectively, George Lincoln Goodale presided over this great organization at the Indianapolis meeting in 1890 , and now to these three great names in American botany his associates in science have regarded the work of William G. Farlow as meriting his election to the highest honor it is within their power to confer upon him.

\section{TO OUR SUBSCRIBERS}

This is the last issue of the year-the fifty-ninth of the Scientific American's life. Since the subscription of many a subscriber expires, it will not be amiss to call attention to the fact that the sending of the paper will be discontinued if the subscription be not renewed. In order to avoid any interruption in the receipt of the paper, subscriptions should be renewed before the publication of the first issue of the new year. To those who are not familiar with the Supplement a word may not be out of place. The SuPPLEMent contains articles too long for insertion in the Scientific American, as well as translations from foreign periodicals, the information contained in which would otherwise be inaccessible. By taking the ScIentific American and Supplement the subscriber receives the benefit of a reduction in the subscription price. 